\title{
Partial diaphragmatic eventration and liver herniation
}

\author{
Emily Morris, Duncan G Fullerton, Gerhard C Bockeler, Dilip Nazareth \\ Mid-Cheshire Hospitals NHS Trust, Crewe, United Kingdom \\ Correspondence: Emily Morris. Address: Mid-Cheshire Hospitals NHS Trust, Middlewich Road, Crewe CW1 4QJ, United \\ Kingdom. Email: emilymorris@doctors.org.uk
}

Received: January 9, 2014

DOI : $10.5430 /$ crim.v1n2p41
Accepted: February 20, $2014 \quad$ Online Published: March 21, 2014

URL: http://dx.doi.org/10.5430/crim.v1n2p41

\section{Abstract}

This case reports a 54-year-old lady with a chest X-ray showing a lung mass that was later identified to be eventration or abnormal elevation of a part of the diaphragm. This article discusses eventration of the right diaphragm and liver herniation, that although relatively rare, has characteristic radiological appearances.

\section{Keywords}

Eventration, Diaphragmatic hernias, Liver herniation

\section{I ntroduction}

Diaphragmatic eventration is a congenital anomaly consisting of development failure of the diaphragm, which can affect part or the entire diaphragm. Radiologically and clinically this refers to an abnormal elevation of an area of intact diaphragm as a result of paralysis, aplasia, or atrophy of varying degrees of the diaphragmatic fibres ${ }^{[1]}$. Rarely, viscera might herniate through this diaphragmatic defect into the chest and can mimic a lung mass. The incidence of diaphragmatic eventration is uncertain, but is estimated at around 1 per 10000 adults ${ }^{[2]}$. It is typically asymptomatic, but can cause dyspeptic, respiratory or cardiac symptoms, including shortness of breath and cough secondary to compression of the lung, and palpitations due to mediastinal displacement ${ }^{[3]}$.

\section{Case presentation}

A 54-year-old fit and well teacher who had never smoked and had no respiratory symptoms was referred to the cancer service with an abnormal chest X-Ray, following an admission with collapse associated with diarrhoea and dehydration. The X-Ray performed at that time showed a right lower lobe opacity (see Figure 1), and a follow up chest X-Ray 8 weeks later demonstrated no change in the appearance. Appropriately, a CT scan was arranged to further investigate the abnormality (see Figure 2). This result was subsequently shown to be inconclusive due to significant movement artifact, and a raised BMI, making interpreting the nature of the opacity difficult.

The patient then went on to have an ultrasound of the diaphragm, which demonstrated right-sided diaphragmatic weakness and the possibility of the liver protruding through it (see Figure 3). A MRI scan (see Figure 4) confirmed the 'lung shadow' to be liver tissue, and demonstrated liver herniation through the diaphragm. 


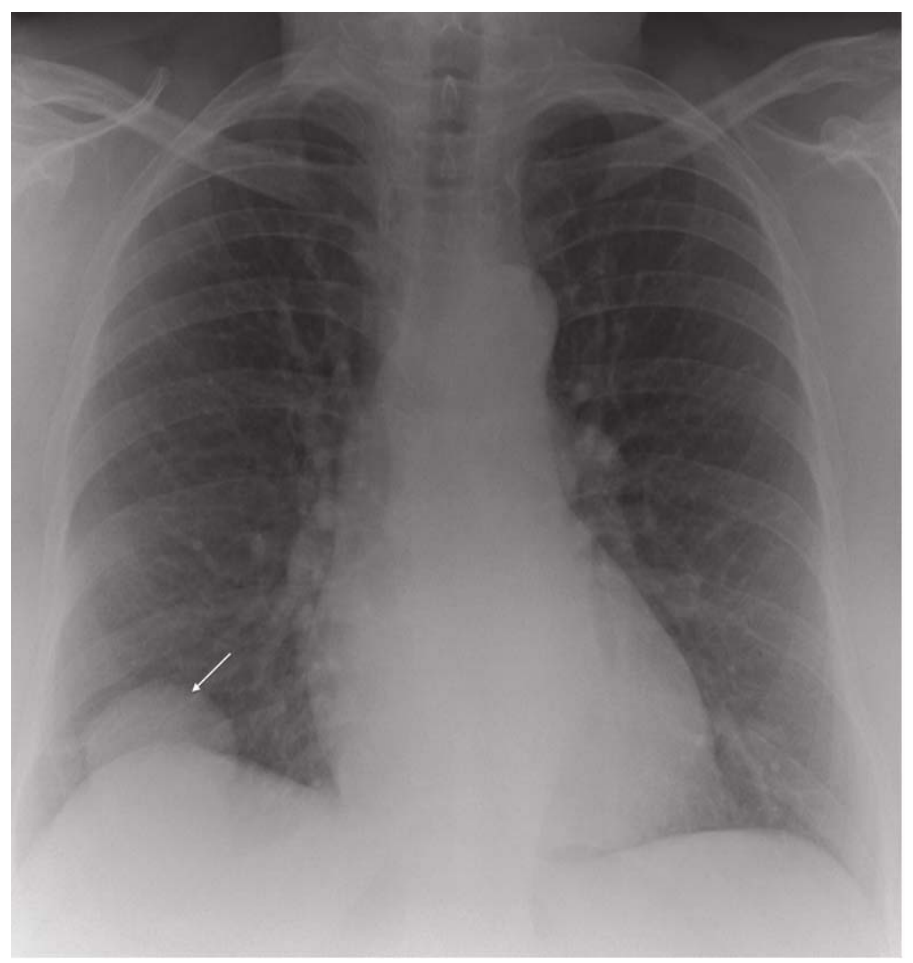

Figure 1. Chest X-Ray showing right lower lobe mass (arrow)

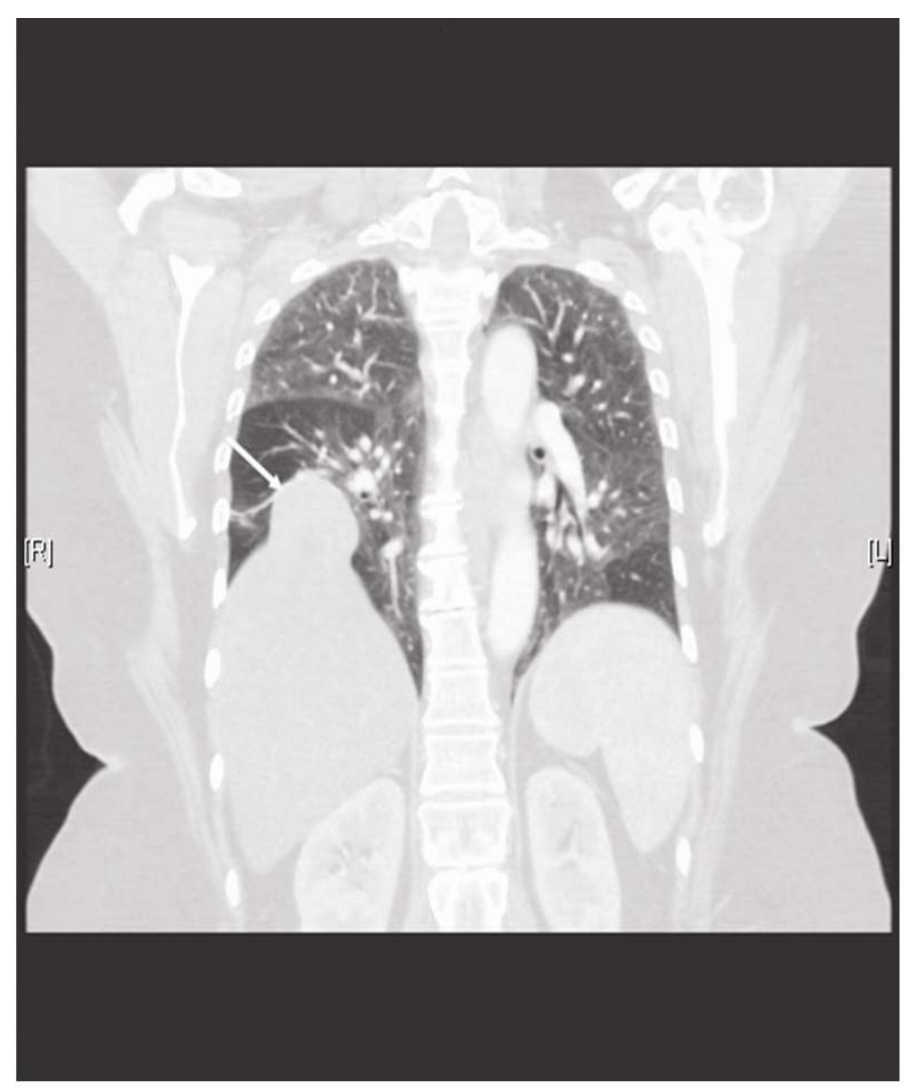

Figure 2. CT scan showing liver herniation (arrow) 


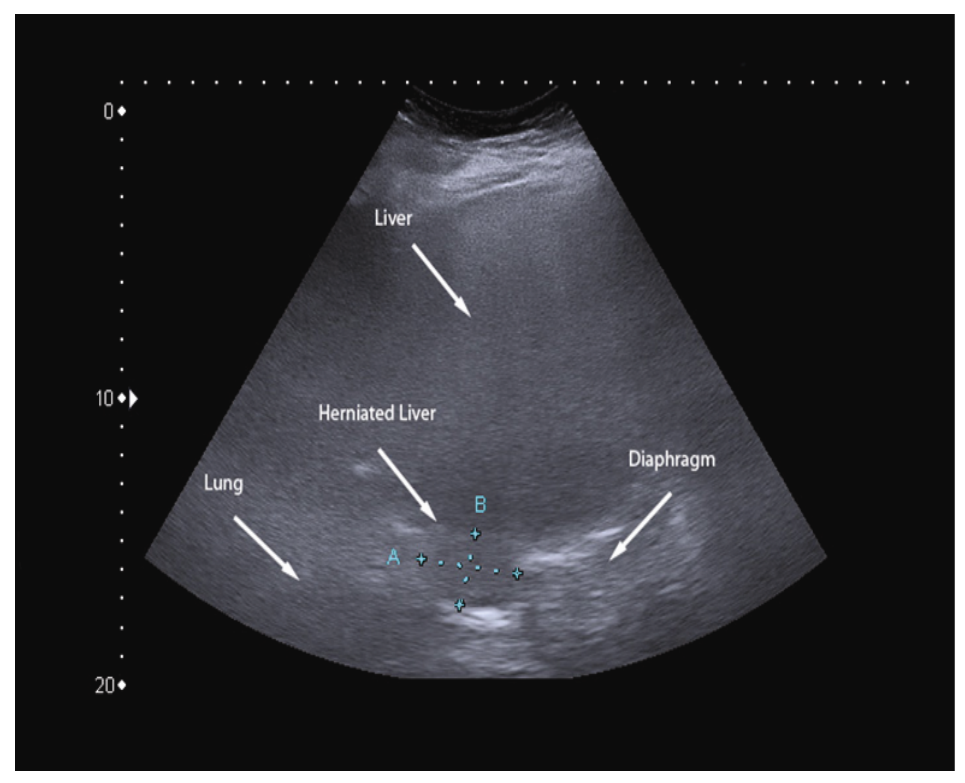

Figure 3. Ultrasound scan showing liver herniation into lung

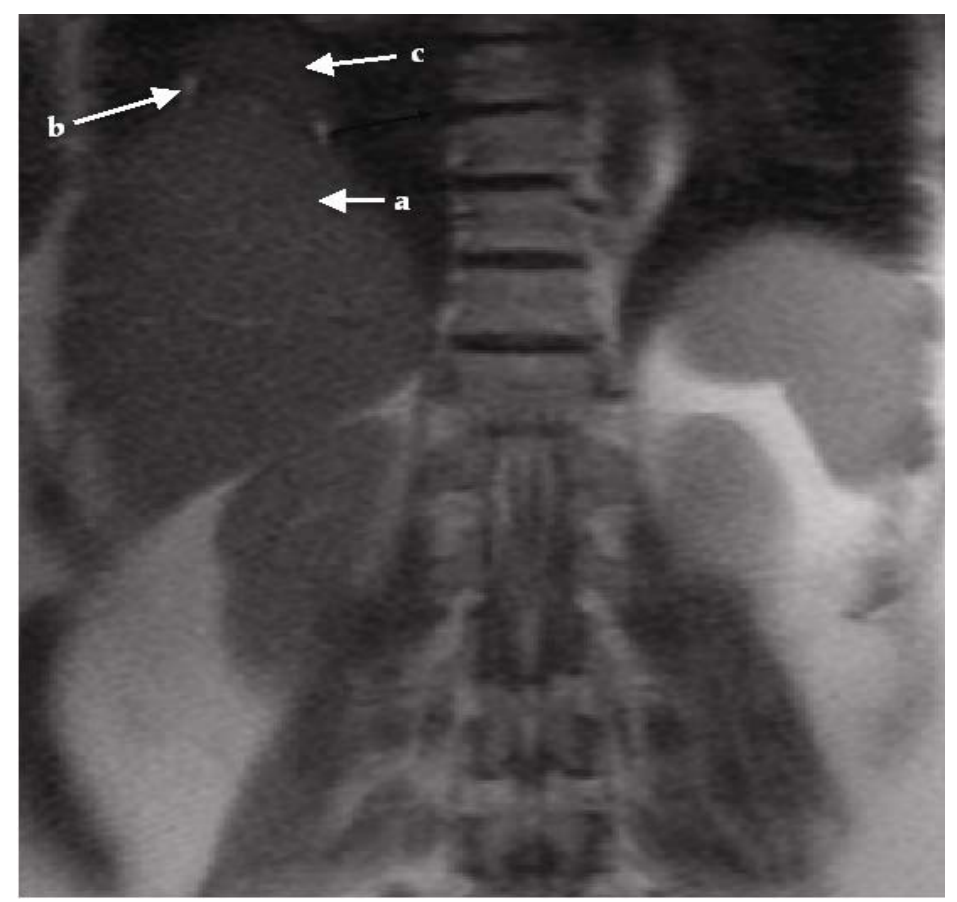

Figure 4. MRI scan demonstrating the liver (a), eventrated diaphragm (b) and herniated liver (c)

\section{Discussion}

Diaphragmatic eventration is a condition usually diagnosed by ultrasonography ${ }^{[4]}$, where the diaphragm can be seen as a thin layer above the abdominal viscera that is usually elevated, and the abnormal region can be seen to move downward with the normal portion ${ }^{[5]}$. Asymptomatic cases, usually diagnosed incidentally, as in this case, are managed conservatively. Surgery is the mainstay of treatment in those who are symptomatic. 
This case serves as reminder that appropriate and targeted imaging is needed in the evaluation of lesions with suspected appearances of 'lung masses'. However not all lung opacities are lung cancer, and a broader differential should always be considered.

\section{References}

[1] Thomas, T.V., Congenital eventration of the diaphragm. Ann Thorac Surg. 1970; 10(2): 180-92. http://dx.doi.org/10.1016/S0003-4975(10)65584-1

[2] Irene, M.I, Booker, P.D., Congenital diaphragmatic hernia and eventration of the diaphragm. Neonatal Surgery, 3rd ed. London: Butterworth; 1990. $214 \mathrm{p}$.

[3] Christensen, P., Eventration of the Diaphragm. Thorax. 1959; 14: 311. http://dx.doi.org/10.1136/thx.14.4.311

[4] Laxdal, O.E., D.H. Mc, and G.W. Mellin, Congenital eventration of the diaphragm. N Engl J Med. 1954. 250(10): 401-8. http://dx.doi.org/10.1056/NEJM195403112501001

[5] Gierada, D.S., R.M. Slone, and M.J. Fleishman, Imaging evaluation of the diaphragm. Chest Surg Clin N Am. 1998. 8(2): $237-80$. 